\title{
The Scylla and Charybdis of Oral anticoagulant Treatment
}

\begin{abstract}
$\mathrm{T}$ REATMENT with oral anticoagulant drugs (i.e., coumarin derivatives such as warfarin) is effective in the prevention of venous and arterial thromboembolism. In patients with atrial fibrillation, anticoagulation reduces the risk of stroke by 70 percent. ${ }^{1}$ The principal problem with anticoagulation is the variability of the effect of coumarin derivatives on the hemostatic system; patients may require very different doses (up to 10 -fold differences) to reach the same level of anticoagulation, and the required dose may also vary over time in an individual patient. Since underanticoagulation is ineffective and overanticoagulation may lead to hemorrhage, anticoagulant treatment needs to be monitored and adjusted to steer safely between the Scylla of thrombosis and the Charybdis of bleeding. The realization that such monitoring requires experience and specialization led to the emergence of anticoagulation clinics as early as the 1950s in the Netherlands, and more recently in Italy, Canada, and the United States. There is no doubt that monitoring by specialized anticoagulation clinics improves the quality of care and reduces the rate of complications; when adequately controlled, oral anticoagulant therapy is effective and safe. ${ }^{2}$
\end{abstract}

Two major issues remain to be resolved. First, what intensity of anticoagulation should be the goal for each of the indications for this therapy? The introduction of the international normalized ratio (INR), ${ }^{3}$ an international standard for measuring the anticoagulant effect of therapy that allows prothrombin-time ratios measured with different thromboplastins to be compared, has made it possible to perform and interpret studies of the optimal intensity of anticoagulant therapy. The second question is whether it is advantageous to use other antithrombotic drugs, notably aspirin, either alone or in combination with oral anticoagulants, in the treatment of arterial disease. Both questions arise from the desire to obtain the best benefit-risk profile: to prevent thrombosis as effectively as possible while causing as little bleeding as possible.

In this issue of the Journal, Hylek and colleagues ${ }^{4}$ report on their investigation of the optimal intensity of oral anticoagulation to prevent ischemic stroke in patients with nonrheumatic atrial fibrillation. They studied 74 patients with atrial fibrillation who had had a stroke even though they were receiving anticoagulant therapy, and compared the intensity of anticoagulation (as indicated by the INR) with that in a random sample of patients who were recciving anticoagulant therapy for atrial fibrillation but who did not have strokes. The risk of stroke was minimal at INRs of 2.0 or higher. This risk increased sharply 
when the INR fell bclow 2.0, whereas therc was no further protection with more intense anticoagulation.

Hylek and coworkers used a case-control approach, which has the advantage that the inclusion of even a relatively small number of case patients can yield the person-time equivalent of a very large follow-up study. It is important to note that with this approach a cross section of patients without stroke should be sampled as controls (as Hylek et al. did), rather than a cross section of their INR values, since under- and overanticoagulated patients are usually seen more frequently in the clinic than are patients with a stable degree of anticoagulation. Sampling patients and examining their previous INR values has been called the "cross section of the files" method, ${ }^{5}$ which takes into account the different intervals for monitoring different patients. Despite its advantages, the case-control approach has two disadvantages. First, the results apply only to one side of the spectrum - in this case, to ischemic strokes and not to hemorrhagic complications. And second, only relative risks can be estimated and not absolute rates of disease. So it cannot be directly inferred from the study by Hylek and colleagues which intensity of anticoagulant treatment is associated with the lowest risk of all untoward events. Several other reports make such estimates possible, however.

In two previous studies, INR-specific rates of complications were calculated according to a persontime method within a cohort. ${ }^{6}$ The first study was conducted among patients with mechanical heart valves who were routinely treated in four Dutch anticoagulation clinics. ${ }^{7}$ The second was the European Atrial Fibrillation Trial, a study of secondary prevention in patients with atrial fibrillation who had previously had a minor stroke. ${ }^{8}$ The latter study, although it included far fewer patients with strokes than the study by Hylek et al., reported very similar results with respect to the risk of stroke, which increased at INR values below 2.0. The risk of hemorrhage increased at INRs above 4.5. For patients with mechanical heart valves, the optimal level of anticoagulation was slightly more intense; the incidence of thromboembolism increased at INR values below 2.5 , and bleeding increased at values of 4.5 or higher.?

In patients with atrial fibrillation, therefore, the INR should be maintained at all times between 2.0 and 4.5 , and in patients with mechanical heart valves it should be held between 2.5 and 4.5 . With some margin of safety built in at both ends, reasonable target ranges for the INR are 2.5 to 3.5 (target, 3.0) for patients with atrial fibrillation, and 3.0 to 4.0 (target, 3.5) for those with mechanical heart valves. Interestingly, researchers have pinpointed these optimal levels through observational studies (both follow-up and case-control) and not by means of randomized trials. Because of the variability of the effect of anticoagulant therapy, the optimal intensity of anticoagulation cannot be easily studied in a randomized fashion. ${ }^{6}$ Moreover, even if the variability of effect were overcome by including very large numbers of patients, an endless series of randomized trials, cach with a slightly different target INR, would be requircd.

As Hylek and coauthors point out, these accumulating data put an end to the push for ever lower intensities of anticoagulation, and indeed a study with a lower target (the Stroke Prevention in Atrial Fibrillation III trial, with a target INR range of 1.2 to 1.5) was recently terminated prematurcly because there was too little clinical effect of treatment.'

Aspirin is an antithrombotic agent that inhibits platelet aggregation. It prevents thrombosis but appears to be less effective than oral anticoagulation for virtually all indications, including the prevention of thromboembolism in patients with atrial fibrillation. Its great advantages are that no monitoring is needed and that it is associated with a lower risk of hemorrhage than are oral anticoagulants. Several studies have compared aspirin with warfarin, and together with other studies of these agents, they point to a higher overall reduction in the risk of cardiovascular events (including both thromboembolism and hemorrhage) with oral anticoagulants. ${ }^{10-12}$

It is still unclear whether the risk of hemorrhage increases with age, 7,13 but elderly patients with atrial fibrillation are certainly at the highest risk for ischemic stroke and will benefit most from oral anticoagulant therapy. The first choice for antithrombotic therapy in all patients with atrial fibrillation is therefore an oral anticoagulant agent. Treatment should be monitored by specialized anticoagulation clinics to minimize risks. Only if good control of the intensity of anticoagulation is not possible, or for the exceptional patient who has a high risk of bleeding or whose compliance is expected to be poor, may aspirin be the drug of choice.

Several studies are under way, both in patients with atrial fibrillation and in patients with mechanical heart valves, to investigate the efficacy of the combination of oral anticoagulants and aspirin. The hypothesis that anticoagulation at a moderate intensity combined with inhibition of platelet aggregation may have beneficial clinical effects is worthy of testing. So far, however, combination therapy has not been found to be superior to well-controlled anticoagulant treatment., 14-16 Therefore, the time has not yet arrived for this combination therapy to be used in routine clinical practice.

The optimal intensity of oral anticoagulation that can now be recommended for various indications takes the form of ranges around target levels. We still need to increase the proportion of INR values that arc actually within these optimal ranges. The next step will be to define individualized levels of antico- 
agulation for patients with different risk profiles, a step that may eventually lead to individually customized anticoagulant treatment.

F.R. RosendaAL, M.D.

Unversity Hospital Leiden NL 2300 RC Lerden, the Netherlands

\section{REFERENCES}

1. Risk lactors for stroke and cfficacy of antuthrombotic thuapy in atural tibrillation analysis of poolcd data from tive randomized controlled tisals Aich Intcin Mcd 1994,154 144957 [Erratum, Ach Intern Mcd 1994, 1542254 ]

2. Cortelaz7o S, tina// G, Viero P, et al Thiombotic and hemourhagx complications in patients with inechankal heart valve piosthesis attending an anticongulation cline Thromb Hacmost 1993,69 31620

3. Intunational Committec for Standardization in Hdcmatology, Interna tronal Committec on 1 hrombosis and Hacmostass ICSH/ICTH tecommendations for scportung prothombin wme 111 or al anticoagulant control Thromb Hacmost 1985,531556

4. Hylch EM, Skatcs SJ, Shechan MA, Singer DE An analysis of the lowcst effuctive intensity of prophylactic anticoagulation for paticnts with non theumatic atıal tibrillation $N$ lengl J Med 1996,335 5406

5. van den Besselaan AMPH Recommended method for teportung therapeu tic control of oral anticoagulant the apy Thomb Hacmost 1990,63 3167

6. Rosendaal FR, Cannegeter SC, van der Meer FJM, Briet E A method to detcrmme the optimal intensity of oral anticoagulant therapy Thromb Hacmost $1993,69236-9$

7. Cannegicter SC, Rosendaal FR, Wntzen AR, van der Mecı FJM, Van dusbrouke JP, Buct E Optimal oral inticongulant thuapy in patients with mechancal heart valves $N$ Engl J Med 1995,333117

8. The Furopean Atrial Fibrillation Trial Study Group Optimal oral anti coagulant therapy in patients with nonrhemmatic atrial fibullation and rc cont cecbral ischema N Fngl J Med 1995,333 510

9. McAnulty J Achusted dose warfan in risus low intensity, fived dose warfarn plus aspirm fon high isk patients with atrial fibrillation the Stroke Pievention in Atial Fibillation III Randomizd Cluncal Find Prescinted at the Amenkan College of Cardiology Annual Meeting, Orlando Fla, March 24-27, 1996

10. Peteisen P, Boysen $G$, Godtfredsen I, Andusun ED, Andersen B Pla cubo controlled, randomisud trial of warfarm and aspun for prevention of thromboembolic complications in chronk atrial fibullation the Copen hagen AFASAK study Lancet 1989,1 1759

11. Stiokc Pievention in Atıal Fibrillation Investıgators Stroke Preventron 1 in Atrial Frbullation Study final rcsults Cinculation 1991,84527 39 12. Wat farun versus aspun for prevention of thrombocmbolism in atral fibrillation Stroke Prevention in Atrial Fibillation Il Study Lancet 1994 , 34368791

13. Flhn SD, Callahan CM, Martm DC, McDonell MB, Honkoff JG,

White RH The isk for and severty of bleding complications in elderly paticnts treated with warfan Ann Inten Med 1996,1249709

14. Turpie AGG, Gent M, Laupacis A, et al A compaison of aspirin with placcloo in patients treated with wartain aftcr heart valve ieplacement N Fngl J Med 1993,329 5249

15. Alman R, Rouver J, Guifinkel E, et al Comparison of two levels of anticoagulant therapy in paticnts with substitute heart valves $\mathrm{J}$ Thorac Cardtovase Surg 1991,101 427 3]

16. Cannegeter SC, Rosendaal FR Optumal oral anticoagulation for pa ticnts with mechanical heart valves N Engl J Med 1995,333 1505

(c) 1996, Massachusetts Mcdical Society

OCopyright, 1996, by the Massachusetts Medical Society Printed in the U.S.A. 
THE NEW ENGLAND JOURNAL OF MEDICINE is published weekly in the English language by the Massachusetts Medical Society (Waltham, MA, USA) Material printed in the Journal is covered by copyright No part of this reprint may be reproduced or transmitted in any form without written permission All rights reserved Direct permission requests to the Permissions Department at the USA subscription office Editorial office 10 Shattuck Street, Boston, MA 02115, USA SUBSCRIPTIONS: SubscriptIon offices 1440 Main Street, Waltham, MA 02154-1649, USA, 1800 Ironstone Manor, Pickering, Ontario, LiW 3J9, Canada, and c/o EMD GmbH, Zeitschriftenvertrieb, Attn Doreen Haak,
Knesebeckstr 96, 10623 Berlın, Germany Subscriptıon prices USA $\$ 10900$ per year (interns, residents $\$ 6500$ per year, students $\$ 5200$ per year, institution $\$ 14500$ per year) In Canada Canadian dollars drawn on Canadian bank C\$165 85 per year (interns, residents $C \$ 11717$ per year, students $C \$ 9737$ per year, C\$197 95 per year) Canadian price includes $7 \%$ GST (\#123397390) Outside USA and Canada in US dollars \$17300 (Interns, residents and students $\$ 11200$, institution $\$ 20700$ ) Please write for detalls about subscription pricing in other currencles Rates are subject to change without notice Sample copies avallable upon request 